\title{
Pulmonary hypertension leading to right heart failure in a patient with iga gammopathy
}

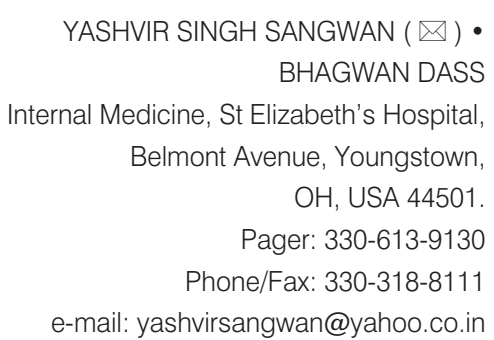

YASHVIR SINGH SANGWAN $(\square) \bullet$
BHAGWAN DASS Belmont Avenue, Youngstown, OH, USA 44501. Phone/Fax: 330-318-8111 e-mail: yashvirsangwan@yahoo.co.in

YASHVIR S. SANGWAN • BHAGWAN DASS

\begin{abstract}
Amyloidosis is a rare disorder characterized by the deposition of amorphous, extracellular, insoluble fibrillar protein in various tissues of the body. Pulmonary hypertension usually occurs in the last stages of the disease with co-existing left ventricular failure. Amyloidosis causing pulmonary hypertension in a patient with no evidence of left ventricular failure is rarely mentioned in literature. Here, we present a patient with IgA gammopathy presenting with pulmonary hypertension leading to progressive right heart failure and death.
\end{abstract}

Key words: amyloidosis, pulmonary hypertension, IgA gammopathy

\section{The case}

Our patient is a 73-year-old AfricanAmerican lady who has had several hospital admissions over the past 2 years with the diagnosis of Congestive Heart Failure (CHF). The patient was on home oxygen therapy for CHF and coumadin therapy for atrial fibrillation. In September 2005 the patient suddenly worsened with severe and progressive shortness of breath (SOB) and increasing leg edema. Her weight increased from 72.5 $\mathrm{kg}$ to $113 \mathrm{~kg}$ and she became immobile. A 2-D echocardiogram revealed an ejection fraction (EF) of $55 \%$, paradoxical septal motion with right ventricular overload, severe right atrial and ventricular dilatation, severe tricuspid regurgitation, mild-to-moderate pulmonary insufficiency, right ventricular (RV) end-diastolic pressure of $75 \mathrm{mmHg}$ and severe pulmonary hypertension of 80 $\mathrm{mmHg}$. She was stabilized with diuretics and sent home. On recurrence of her symptoms she presented to our hospital in November 2005.

The patient had extreme dyspnea with swelling of the legs, thighs and abdomen. Her vital signs were stable. Physical exam of the cardiac and respiratory systems showed a significantly elevated jugular venous distention of $14 \mathrm{~cm}$, bilateral bibasilar crackles, reduced air entry, an irregular heart-beat with a normal S1 and a fixed split S2, a 2/6 to 3/6 holo-systolic murmur (radiating through the whole precordium and changing with respiration), a laterally displaced point of maximal impulse and a right ventricle heave. The abdomen showed significant pulsatile hepatomegaly. The extremities had $4+$ edema with chronic skin changes. Shotty adenopathy was seen in the cervical area and in the left supraclavicular area. Computed Axial Tomography (CAT) scan of the abdomen and pelvis showed abdominal ascites, small bilateral pleural effusions with pleural scarring, focal aneurysms and dilatation of the splenic artery measuring up to $3 \mathrm{~cm}$ in size and dense calcification and granulomatous changes of the spleen. Electrocardiogram (ECG) showed normal sinus rhythm, incomplete right bundle branch block, T wave inversion in V1, V2, and V3 and RV hypertrophy.

We attempted to find the etiology of pulmonary hypertension and isolated right heart failure in this patient. There was no CAT scan evidence for chronic thrombo-embolic pulmonary disease or chronic obstructive pulmonary disease. A trans-esophageal echocardiogram (TEE) confirmed the echocardiogram findings and also revealed a possibility of patent foramen ovale. An extensive workup for Connective Tissue Disease explaining the pulmonary hypertension was non-diagnostic. A Sleep study showed only mild sleep apnea. The calcifications in the spleen could not be explained, as there was no old evidence of either sarcoid or histoplasmosis or old tuberculosis on 
the imaging studies. Chronic fibrosing mediastinitis could be the only cause of the calcifications that could explain the significant right-sided heart failure. Other differential diagnoses entertained were vasculitis, amyloidosis and multiple myeloma.

Serum and urine protein electrophoresis with immunofixation revealed IgA gammopathy with normal lgM and lgG. The tests showed IgA lambda M-protein spike of $1900 \mathrm{mg} / \mathrm{dl}$, lgG $1252 \mathrm{mg} /$ dl (normal range 620-1400 mg/dl), lgM $179 \mathrm{mg} / \mathrm{dl}$ (normal range 45-250 mg/dl) and IgA 963 mg/dl (normal range 80$350 \mathrm{mg} / \mathrm{dl}$ ). Gamma globulin was 1.9 $\mathrm{gm} / \mathrm{dl}$ (normal range 0.7-1.6 gm/dl).

With the possibility of amyloidosis as a cause for the patient's symptoms, it was decided to biopsy the supraclavicular adenopathy but the patient refused this procedure. Bone marrow biopsy was not done due to the patient's poor status. The patient continued to have increasing respiratory distress and hypoxia despite medical treatment. She was made a Do-Not-Resuscitate (DNR) patient and expired in a nursing home in a few days.

\section{Amyloidosis}

\section{Introduction}

Amyloidosis is a disorder characterized by the deposition of amorphous, extracellular insoluble fibrillar protein in various tissues of our body causing widespread organ dysfunction and death (1). There are different types of subunit proteins - mainly AL and AA. $A L$ is derived from the light chain of a monoclonal immunoglobulin and is seen in both primary and myeloma amyloidosis. AA is seen in secondary amyloidosis associated with chronic inflammatory diseases such as renal disease, syphilis, inflammatory bowel disease, rheumatoid arthritis, bronchiectasis, leprosy, osteomyelitis and certain cancers (2). End-stage renal disease and dialysis is associated with B-2 M amyloid and familial or senile amyloidosis show ATTR (transthyretin) amyloid. All amyloids bind Congo red, produce apple green birefringence under polarized light and have a bpleated structure.

\section{Incidence}

Immunoglobulin amyloidosis is rare with an incidence of 8 patients per million persons a year (3). 99\% of patients are above the age of 40 years. (2)

\section{Diagnosis}

The initial screening is with immunoelectrophoresis and immunofixation of the serum and urine (4) revealing a monoclonal light chain in $90 \%$ of patients (5). In the rest, a subcutaneous fat aspirate, bone marrow biopsy or biopsies of the minor salivary glands will detect amyloid in $70-90 \%$ of patients (6). The bone marrow almost always will show a clonal population of plasma cells detectable by immunohistochemistry and immunoflourescence $(7,8)$. Direct biopsy of the affected organ will most likely be positive (9) although not usually needed (10). Radionuclide scans using radio labeled amyloid $P$ component are capable of binding to amyloid deposits (11).

\section{Clinical introduction}

Fatigue, weight loss and periorbital purpura are the most common presenting symptoms (10). Consequently, a large proportion of these patients undergo detailed searches for an underlying occult malignancy (1). Macroglossia, the most specific physical finding, is positive only $9 \%$ of the time.

The four most common "syndromes" in immunoglobulin amyloidosis are: nephrotic range proteinuria (12), congestive heart failure (CHF) (5), unexplained hepatomegaly (13) and idiopathic peripheral neuropathy (14).

Kidney is the most frequently affected organ (35-50\% patients) (15) usually presenting as unexplained nephrotic syndrome (16). Renal amyloidosis is seen in $10 \%$ of renal biopsies of non diabetics with nephrotic syndrome (12).

Cardiac involvement is seen in $25 \%$ patients, usually with unexplained $\mathrm{CHF}$. Restrictive cardiomyopathy is seen in late stages (5). There is no systolic dys- function till late in the disease. Echocardiogram frequently shows diastolic dysfunction, septal thickness of $>12 \mathrm{~mm}$ (88\% patients) $(17,18)$, ventricular wall thickness $>15 \mathrm{~mm}$ (19) and thickening of mitral and tricuspid valves. ECG usually shows low voltage (20) and QS complexes in leads V1 - V3 may be seen and interpreted falsely as a silent myocardial infarction (21).

$16-25 \%$ of patients have hepatomegaly disproportionate to liver function tests abnormalities (22). Ascites is seen because of associated nephrotic syndrome and not due to portal hypertension as patients die of extrahepatic amyloidosis before portal hypertension can develop. Cholestatic jaundice is usually a preterminal finding. $(23,24)$.

Salivary gland involvement can cause xerostomia $(25,26)$. Gastric amyloidosis with nausea, vomiting and weight loss was seen in 8 and gastroparesis was seen in 3 of 769 patients in one series (27). Less than $5 \%$ of patients will show malabsorption. Amyloidosis can rarely present as pseudo-obstruction or ischemic colitis $(28,29)$. Luminal narrowing and loss of haustrations are the most common radiological findings (30).

Peripheral neuropathy, usually in the lower extremities, is seen in $17 \%$ of patients. Muscle weakness (from neuropathy or vascular occlusion) and autonomic dysfunction are seen in approximately $65 \%$ of patients each. Muscle infiltration and pseudohypertrophy can be seen $(31,32)$. Rarely temporal artery involvement may mimic giant cell arteritis. Calf, limb and jaw claudication might be seen (33-35). Fragile infiltrated blood vessels cause purpura and bleeds.

The respiratory system and gas exchange are usually preserved till late in the disease. Pulmonary amyloidosis may be localized or be a manifestation of systemic involvement. Local disease is classified as tracheobronchial, solitary nodular, multiple nodular and diffuse parenchymal (rare) (36). Patients may have dyspnea at rest or exertion and dry cough. Chest X-ray (CXR) may have features of interstitial lung dis- 
ease. Amyloid deposits are seen on biopsy and may be predominant in the vascular walls or alveolar septa or both (37).

Hematological abnormalities like factor $X$ deficiency, prolonged prothrombin time, platelet defects, decreased alpha 2 plasmin inhibitor, increased plasminogen may be seen $(38,39)$.

\section{Pulmonary hypertension}

A Mayo Clinic study has reported 5 cases with the rare presentation of amyloidosis and pulmonary hypertension $(\mathrm{PH})$ in patients with no secondary cause for $\mathrm{PH}$ and no evidence of left ventricle dysfunction. $\mathrm{PH}$ was found a median 73 days before death (2).

In patients with diffuse pulmonary amyloidosis, $\mathrm{PH}$ can be caused by either severe vessel wall infiltration with amyloid or by amyloid deposition in the alveolar septa, causing obliteration of a significant proportion of the pulmonary capillary bed and pulmonary HTN developing concurrently with lung volume restriction (40).

\section{Prognosis}

Cardiac disease is the most relevant prognostic factor (41-43). 50\% of patients will die of cardiac causes - CHF, ventricular fibrillation or asystole (44). A bad prognosis is seen in patients with EF < $50 \%$, Creatinine $>1.3$, neuropathy and diastolic dysfunction.

\section{Therapy}

Despite therapy, the median survival is only 17 months after diagnosis. In comparison, good-responders to treatment survive a median 90 months (6). Cycles of mephalan and prednisone are the treatment of choice (45). Response is measured by a $50 \%$ reduction in either urinary protein excretion or $\mathrm{M}$ component or light chain or amyloid precursor protein or serum alkaline phosphatase or a $2 \mathrm{~mm}$ reduction in cardiac wall thickness. Approximately $6.5 \%$ of patients exposed to melphalan develop a myelodysplastic syndrome. Median survival from onset is 8 months. Heart transplantation is effective for amyloidosis $(46,47)$ with reported survival of 69-118 months. Myeloablative therapy with stem cell reconstitution (48) could work but has a treatment related mortality of $30-40 \%$ (49).

\section{Conclusion}

Amyloidosis should be considered in patients older than 40 years who have unexplained nephrotic syndrome, heart failure, idiopathic peripheral neuropathy or hepatomegaly. Diffuse pulmonary amyloidosis should be considered in the differential of unexplained pulmonary hypertension, especially in patients with systemic amloidosis or multiple myeloma.

\section{REFERENCES}

1. Gertz MA, Kyle RA. Primary systemic amyloidosis - a diagnostic primer. Mayo Clin Proc 1989;64:1505-19.

2. Kyle RA, Greipp PR. Amyloidosis (AL). Clinical and laboratory features in 229 cases. Mayo Clin Proc 1983;58:665-83.

3. Hawkins PN. The diagnosis, natural history and treatment of amyloidosis. J R Coll Physicians Lond 1997;31:552-60.

4. Pascali E. Diagnosis and treatment of primary amyloidosis. Crit Rev Oncol Hematol 1995;19:149-81.

5. Kyle RA, Gertz MA. Primary systemic amyloidosis clinical and laboratory features in 474 cases. Semin Hematol 1995;32:45-59

6. Gertz MA, Kyle RA, Greipp PR. Response rates and survival in primary systemic amyloidosis. Blood 1991;77:257-62.

7. Gertz MA, Greipp PR, Kyle RA. Classification of amyloidosis by the detection of clonal excess of plasma cells in the bone marrow. J Lab Clin Med 1991;118:33-9.

8. Wu SS, Brady K, Anderson JJ, Vezina R, Skinner M, Neiman RS, et al. The predictive value of bone marrow morphologic characteristics and immunostaining in primary (AL) amyloidosis. Am J Clin Pathol 1991;96:95-9.

9. Westermark P. Diagnosing amyloidosis. Scand J Rheumatol. 1995;24:327-9.

10. Gertz MA, Grogan M, Kyle RA, Tajik AJ. Endomyocardial biopsy-proven light chain amyloidosis (AL) without echocardiographic features of infiltrative cardiomyopathy. Am J Cardiol 1997;80:93-5.

11. Gillmore JD, Hawkins PN, Pepys MB. Amyloidosis: a review of recent diagnostic and therapeutic developments. Br J Haematol 1997;99:245-56.

12. Schena FP, Pannarale G, Carbonara MC. Clinical and therapeutic aspects of renal amyloidosis. Nephrol Dial Transplant 1996;11:63-8.

13. Peters RA, Koukoulis G, Gimson A, Portmann B, Westaby D, Williams R. Primary amyloidosis and severe intrahepatic cholecystatic jaundice. Gut 1994;35:1322-5.

14. Rajkumar SV, Gertz MA, Kyle RA. Prognosis of patients with primary systemic amyloidosis who present with dominant neuropathy. Am J Med 1998;104:232-7.

15. Gertz MA, Kyle RA. Prognostic value of urinary protein in primary systemic amyloidosis. Am J Clin Pathol 1990;94:313-7.

16. Gertz MA, Kyle RA, O'Fallon WM. Dialysis support of patients with primary systemic amyloidosis. A study of 211 patients. Arch Intern Med 1992;152:2245-50.

17. Siqueira-Filho AG, Cunha CL, Tajik AJ, Seward JB, Schattenberg TT, Giuliani ER. M-mode and two-dimensional echocardiographic features in cardiac amyloidosis. Circulation 1981;63:188-96. 
18. Klein AL, Hatle LK, Burstow DJ, Seward JB, Kyle RA, Bailey KR, et al. Doppler characterization of left ventricular diastolic function in cardiac amyloidosis. J Am Coll Cardiol 1989;13:1017-26.

19. Falk RH, Plehn JF, Deering T, Schick EC Jr, Boinay P, Rubinow A, et al. Sensitivity and specificity of the echocardiographic features of cardiac amyloidosis. Am J Cardiol 1987;59:418-22.

20. Hamer JP, Janssen S, Van Rijswijk MH, Lie Kl. Amyloid cardiomyopathy in systemic non-hereditary amyloidosis. Clinical, echocardiographic and electrocardiographic findings in 30 patients with AA and 24 patients with AL amyloidosis. Eur Heart J 1992;13:623-7.

21. Hancock EW. Low voltage, Q waves, and congestive heart failure. Hosp Pract (Minneap) 1997;32:21-2.

22. Gertz MA, Kyle RA. Hepatic amyloidosis: clinical appraisal in 77 patients. Hepatology 1997;25:118-21.

23. Bujanda L, Beguiristain A, Alberdi F, Cosme A, Ruiz de la Hermosa J, Gutierrez-Stampa, et al. Spontaneous rupture of liver in amyloidosis. Am J Gastroenterol 1997;92:1385-6.

24. Gastineau DA, Gertz MA, Rosen CB, Kyle RA. Computed tomography for diagnosis of hepatic rupture in primary systemic amyloidosis. Am J Hematol 1991;37:194-6.

25. Richey TK, Bennion SD. Etiologies of the sicca syndrome: primary systemic amyloidosis and others. Int J Dermatol 1996;35:553-7.

26. Schlesinger I. Multiple myeloma and AL amyloidosis mimicking Sjogren's syndrome. South Med J. 1993;86:568-9.

27. Menke DM, Kyle RA, Fleming CR, Wolfe JT 3rd, Kurtin PJ, Oldenburg WA. Symptomatic gastric amyloidosis in patients with primary systemic amyloidosis. Mayo Clin Proc 1993;68:763-7.

28. Fraser AG, Arthur JF, Hamilton I. Intestinal pseudoobstruction secondary to amyloidosis responsive to cisapride. Dig Dis Sci 1991;36:532-5.

29. Trinh TD, Jones B, Fishman EK. Amyloidosis of the colon presenting as ischemic colitis: a case report and review of the literature. Gastrointest Radiol 1991;16:133-6.

30. Lee JG, Wilson JA, Gottfried MR. Gastrointestinal manifestations of amyloidosis. South Med J 1994;87:243-7.

31. Gertz MA, Kyle RA. Myopathy in primary systemic amyloidosis. J Neurol Neurosurg Psychiatry 1996;60:655-60.

32. Katz GA, Peter JB, Pearson CM, Adams WS. The shoulder pad sign - a diagnostic feature of amyloid arthropathy. N Engl J Med 1973;288:354-5.

33. Rao JK, Allen NB. Primary systemic amyloidosis masquerading as giant cell arteritis. Case report and review of the literature. Arthritis Rheum 1993;36:422-5.

34. Rodon P, Friocourt P, Blanchet S, Levallois D. Temporal artery involvement revealing AL amyloidosis and IgD monoclonal gammopathy. J Rheumatol 1996;23:189-90.

35. Salvarani C, Gabriel SE, Gertz MA, Bjornsson J, Li CY, Hunder GG. Primary systemic amyloidosis presenting as giant cell arteritis and polymyalgia rheumatica. Arthritis Rheum 1994;37:1621-6.

36. Rubinow A, Celli BR, Cohen AS, Rigden BG, Brody JS. Localized amyloidosis of the lower respiratory tract. Am Rev Respir Dis 1978;118:603-11.

37. Smith RR, Hutchins GM, Moore GW, Humphrey RL. Type and distribution of pulmonary parenchymal and vascular amyloid. Am J Med 1979;66:96-104.

38. Gastineau DA, Gertz MA, Daniels TM, Kyle RA, Bowie EJ. Inhibitor of thrombin time in systemic amyloidosis. Blood 1991;77:2637-40.

39. Mizutani AR, Ward CF. Amyloidosis associated bleeding diathesis in the surgical patient. Can J Anaesth 1990;37:910-2.

40. Shiue ST, McNally DP. Pulmonary hypertension from prominent vascular involvement in diffuse amyloidosis. Arch Intern Med 1988;148:687-9.

41. Gertz MA, Kyle RA. Amyloidosis: prognosis and treatment. Semin Arthritis Rheum 1994;24:124-38.

42. Kyle RA, Greipp PR, O'Fallon WM. Primary systemic amyloidosis: multivariate analysis for prognostic factors in 168 cases. Blood 1986;68:220-4.

43. Chamarthi B, Dubrey SW, Cha K, Skinner M, Falk RH. Features and prognosis of exertional syncope in light-chain associated AL cardiac amyloidosis. Am J Cardiol 1997;80:1242-5.

44. Gertz MA, Lacy MQ, Dispenzeiri A: Amyloidosis. Hematol Oncol Clin North Am 1999;13:1211-33.

45. Kyle RA, Gertz MA, Greipp PR, Witzig TE, Lust JA, Lacy MQ, et al. A trial of three regimens for primary amyloidosis: colchicine alone, melphalan and prednisone, and melphalan, prednisone, and colchicine. N Engl J Med 1997;336:1202-7.

46. Dubrey S, Simms RW, Skinner M, Falk RH. Recurrence of primary (AL) amyloidosis in a transplanted heart with four-year survival. Am J Cardiol 1995;76:739-41.

47. Pelosi F Jr, Capehart J, Roberts WC. Effectiveness of cardiac transplantation for primary (AL) cardiac amyloidosis. Am J Cardiol 1997;79:532-5.

48. van Buren M, Hene RJ, Verdonck LF, Verzijlbergen FJ, Lokhorst HM. Clinical remission after syngeneic bone marrow transplantation in a patient with AL amyloidosis. Ann Intern Med 1995;122:508-10.

49. Moreau P, Leblond V, Bourquelot P, Facon T, Huynh A, Caillot D, et al. Prognostic factors for survival and response after high-dose therapy and autologous stem cell transplantation in systemic AL amyloidosis: a report on 21 patients. Br J Haematol 1998;101:766-9. 